\title{
Synthesis Ofsome Benzothiazole Derivatives and Kinetic Studies of Their Oxidation Using Chloramine-T in Acid Medium
}

\author{
Manikyanahalli Narasigowda Kumara ${ }^{1}$, Muddegowda Harsha ${ }^{2}$ \\ ${ }^{1}$ Department of Chemistry, Yuvaraja's College, University of Mysore, Mysuru 5700 05, India \\ ${ }^{I}$ Department of Chemistry, Saradavilas College, University of Mysore, Mysuru 5700 04, India
}

\begin{abstract}
The kinetics of oxidation of 2-phenyl-benzothiazole (BzlH), 2-(4-methoxyphenyl) benzothiazole $(\mathrm{OMeBzlH}), 2-\left(4-\right.$ nitrophenyl)-benzothiazole $\left(\mathrm{NO}_{2} \mathrm{BzlH}\right)$ by chloramine- $\mathrm{T}$; $(\mathrm{CAT})$ in presence of $\mathrm{HClO}_{4}$ has been investigated at $296 \mathrm{~K}$. Under similar experimental conditions, the oxidation reactions follow identical kinetics for all the three benzothiazoles with first order dependence each on [CAT] ${ }_{0}$ and [substrate $]_{0}$ and inverse fractional order dependence on $\left[\mathrm{H}^{+}\right]$. Solvent composition shows negative effect indicating the involvement of negative ion-dipolar molecule in the rate determining step. Variation of ionic strength of the medium and addition of halide ions had no effect on the reaction rate. Addition of p-toluenesulphonamide (PTS), the reduction product also has no effect on the rate of reaction. The reactions were studied at different temperatures and the composite activation parameters have been computed. Relative reactivity of oxidation of these follow the order: $\mathrm{OMeBzlH}>\mathrm{BzlH}>\mathrm{NO}_{2} \mathrm{BzlH}$. This trend may be attributed to inductive effects. The observed results have been explained by a plausible mechanism and the related rate law has been deduced.
\end{abstract}

Key words: activation parameters, dielectric constant, halide effect, Order,reaction mechanism

\section{Introduction}

Benzothiazole, a well-known heterocyclic compound and also a weak base, which has a varied biological activities and is of great scientific from last few years. Benzothiazole and its derivatives are widely found in medicinal and bioorganic chemistry with various application in drug discovery. Benzothiazolemoites are part of compounds showvarious biological activities such as antimicrobial [1-5], anticancer [6-8,], antidiabetic [9], anthelmintic [10] activities. They also find applications in industry asvulcanization accelerators, anti-oxidants. Various benzothiazoleslike 2-phenylbenzothiazolehas received much attention because of its unique structure and its uses as radioactive amyloid imagining agents [11], and anticancer agents. [12].Benzothiazoles are bicyclic ring system with numerous multiple applications for various purposes. In the 1950s, number of 2-aminobenzothiazoles were studied intensively, as the 2-amino benzothiazole scaffold is one among the privileged structure in medicinal chemistry [11,13] and reported cytotoxic on cancer cells[13]. It is noteworthy that the combination of 2- aminobenzothiazoles with other heterocyclic compounds is a well-known approach in order to design new drug like molecules, which allows achieving new pharmacological profile, action, toxicity lowering. The 2-(4-aminophenyl) benzothiazoles is one of the novel class of potent and e antitumor agents and they display characteristic profile of cytotoxic response along the cell lines. In addition, benzothiazole ring is present in various other compounds like terrestrial or marine natural compounds, which have numerous biological properties. P.R. Bhagat et al., reported kinetics of oxidation of benzothiazoles and its derivatives using ruthenium as catalysis in acid medium. Oxidation products of the reactions are orthanilic acid and its derivatives. On the basis of these observations, we will explore the oxidation and mechanistic investigation of benzothiazole derivatives. But only less information reported in the literature on the oxidation kinetics of benzothiazole derivatives using an oxidant.

Nandibewoor et al., reported the kinetics of oxidation of pyridylmethylsulphinylbenzimidazole by cerium (IV) in perchloric acid medium. Puttaswamy et al., oxidized imidazole, benzimidazole and its derivatives (2-HyBzlH, 2-AmBzlH, and 2-PhBzlH) by sodium-N-chloro-p-toluenesulfonamide (Chloramine-T) using ruthenium chloride as catalyst in acid medium. Oxidation product of the reactions is o-phenylenediamine and benzoic acid. Puttaswamy et al., also reported, oxidation of imidazole, benzimidazole and its derivatives(2$\mathrm{HyBzlH}, 2-\mathrm{AmBzlH}$, and 2-PhBzlH) by sodium-N-chloro-p-toluenesulfonamide (Chloramine-T) using Os(VIII) as catalyst in alkaline medium at room temperature. Oxidation products of the reactions are orthanilic acid and its derivatives. On the basis of these observations, we will explore the oxidation and mechanistic investigation of benzothiazoleand derivatives by Sodium N-chloro-p-toluenesulfonamide (Chloramine-T). The main Objectives were 1. Synthesis of benzothiazole2. Development of efficient synthetic process for the facile conversation of benzothiazole derivatives to corresponding oxidation products. 3. Elucidation of plausible mechanism and to deduce an appropriate rate law. 4. Ascertain the various reactivity species. 5. Finally, assess the relative relativities of the substrates. 


\section{Synthesis Of Benzothiazole Derivatives}

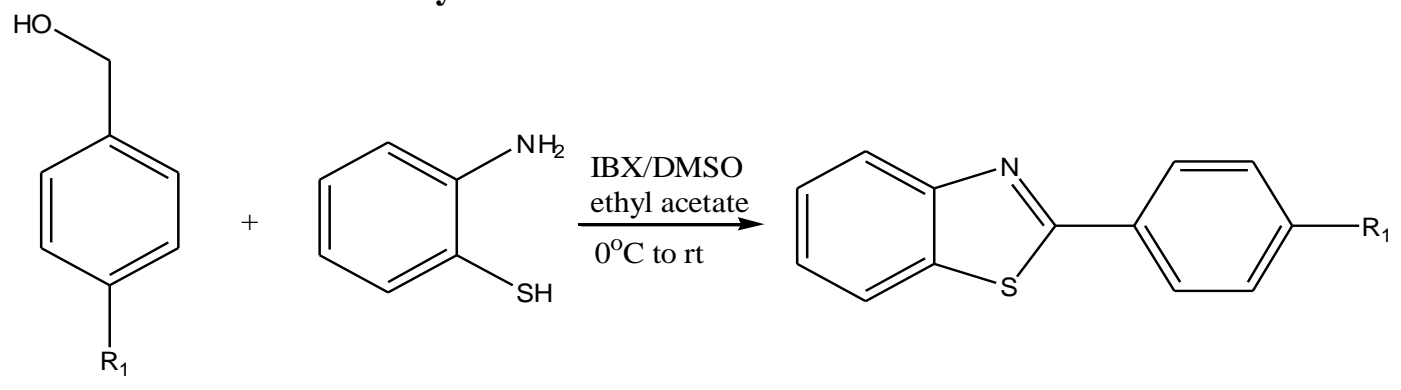

Where $\mathrm{R}_{1}=-\mathrm{H}$ and $\mathrm{R}_{2}=-\mathrm{H},-\mathrm{OCH}_{3},-\mathrm{NO}_{2}$

To a solution alcohol $(0.5-0.6 \mathrm{mmol})$ and IBX (1.1 equiv) were stirred in DMSO at $20^{\circ} \mathrm{C}$. Once the oxidation of alcohol to aldehyde was complete, as judged from TLC analysis, O-aminothiophenol (1.1 equiv) was introduced in to the reaction mixture and the reaction mixture was allowed to stir at room temperature until the aldehyde disappeared. At the end of the reaction, DMSO was removed under high vacuum, and the residue was treated with $1.0 \mathrm{M} \mathrm{NaOH}$ solution until the PH was 6-7. The organic matter was extracted with ethyl acetate. Regular work up followed by silica gel chromatography led to pure benzothiazoles, which were characterized

\subsection{Experimental}

2.1CAT (Sigma Aldrich) was purified by the method of Morris et al [14]. An aqueous solution of CAT was prepared, standardized iodometrically and stored in amber colored stoppered bottles until further use to prevent its photochemical deterioration. The concentrations of stock solutions were periodically determined. An aqueous solution of $\mathrm{NO}_{2} \mathrm{BzlH}, \mathrm{BzlH}$ and $\mathrm{OMeBzlH}$, were freshly prepared whenever required. All other chemicals used were of analytical grade.Triple distilled water was used for preparing solutions.

\subsection{Kinetic measurement}

The kinetic runs were performed under pseudo-first-order conditions by ensuring an excess of CAT over substrate in sodium hydroxide at $296 \mathrm{~K}$ using UV-Vis spectrophotometry (Shimadzu-1800). A constant temperature was maintained with an accuracy of $\pm 0.1^{\circ} \mathrm{C}$. Reactions were carried out in glass stoppered Pyrex boiling tubes whose outer surface were coated black to eliminate any photochemical effects. The oxidant as well as requisite amounts of substrate, $\mathrm{HClO}_{4}$ solutions and water (to keep the total volume constant for all runs) were taken in separate tubes. The absorbance reading were thermo stated for nearly 30 minutes at $296 \mathrm{~K}$. The reaction was initiated by the rapid addition of a measured amount of oxidant to the stirred reaction mixture. $3 \mathrm{ml}$ of aliquot of the solution was pipetted into a cuvette placed in the spectrophotometer. Absorbance measurements were made at $\lambda_{\max }=258 \mathrm{~nm}, 283 \mathrm{~nm}$ and $276 \mathrm{~nm}$ forBzlH, OMeBzlH, $\mathrm{NO}_{2} \mathrm{BzlH}$ respectively for more than $75 \%$ of completion of the reaction. Plots $\log$ (abs) Vs time were made to evaluate the pseudo-first-order rate constants $\mathrm{k}^{\prime}\left(\mathrm{s}^{-1}\right)$. Regression analysis of the experimental data was carried out on fx-991MS scientific calculator to evaluate the regression coefficient.

\subsection{Reaction stoichiometry}

Reaction mixtures containing different ratios of CAT and substrate in $5 \times 10^{-3} \mathrm{~mol} \mathrm{dm}^{-3} \mathrm{HClO}_{4}$ were allowed to react for $24 \mathrm{hrs}$ at $296 \mathrm{k}$. The determination of unreacted CAT in the reaction mixture showed that one mole of the substrate consumed one mole of CAT

\subsection{Effect of varying reactant concentration on the rate}

\section{Resultsand Discussion}

With the oxidant in excess and keeping $[\mathrm{CAT}]_{0},\left[\mathrm{HClO}_{4}\right]$ and temperature constant, plot of $\log (\mathrm{abs}) \mathrm{Vs}$ time was found to be linear $\left(\mathrm{R}^{2}=0.99\right)$ indicating a first order dependence on [subs] $]_{0}$. The values of Pseudo-First order rate constants $\left(\mathrm{k}^{\prime} \mathrm{s}^{-1}\right)$ are listed in Table 1. Also under the same experimental conditions an increase in $[\mathrm{CAT}]_{\mathrm{o}}$ increased the value of $\mathrm{k}^{\prime}$ (Table1). Plot of $\log \mathrm{k}^{\prime} \mathrm{Vs} \log \left[\mathrm{CAT}\right.$ ] were linear $\left(\mathrm{R}^{2}=0.99\right)$ with aslope of 0.92, 0.90 and 0.90 for $\mathrm{NO}_{2} \mathrm{BzlH}, \mathrm{BzlH}, \mathrm{OMeBzlH}$, respectively which indicated a fractional order dependence on [CAT] (Figure 1).

\subsection{Effect of varying $\mathrm{HClO}_{4}$ concentration on the rate}

The effect of $\mathrm{HClO}_{4}$ on the rate of the reaction was studied by varying in the concentration of $\left[\mathrm{HClO}_{4}\right]($ table 1$)$. Plot of $\log \mathrm{k}^{\prime}$ versus $\log \left[\mathrm{HClO}_{4}\right]$ were linear $\left(\mathrm{R}^{2}=0.99\right)$ with a negative slope of $0.52,0.52$ and 0.51 for $\mathrm{NO}_{2} \mathrm{BzlH}, \mathrm{BzlH}, \mathrm{OMeBzlHrespectively} \mathrm{which} \mathrm{indicated} \mathrm{an} \mathrm{inverse} \mathrm{fractional} \mathrm{order} \mathrm{dependence} \mathrm{on}\left[\mathrm{H}^{+}\right]$(Figure 2). 
Table 1. Effect of varying concentrations of oxidant, substrate and medium on the rate at $296 \mathrm{~K}$

\begin{tabular}{|c|c|c|c|c|c|}
\hline \multirow{2}{*}{$\begin{array}{c}10^{4} \times[\mathrm{CAT}] \\
\mathrm{mol} \mathrm{dm}^{3}{ }^{3}\end{array}$} & \multirow{2}{*}{$\begin{array}{c}10^{5} \times[\text { Subs }] \\
\mathrm{mol} \mathrm{dm}^{-3}\end{array}$} & \multirow{2}{*}{$\begin{array}{c}10^{4} \times\left[\mathrm{H}^{+}\right] \\
\mathrm{mol} \mathrm{dm}^{-3}\end{array}$} & \multicolumn{3}{|c|}{$10^{4} \mathrm{k}^{\prime}\left(\mathrm{s}^{-1}\right)$} \\
\hline & & & $\mathrm{NO}_{2} \mathrm{BzlH}$ & BzlH & OMeBzlH \\
\hline 1.0 & 3.0 & 4.0 & 1.98 & 2.33 & 3.01 \\
\hline 2.0 & 3.0 & 4.0 & 3.87 & 4.55 & 5.82 \\
\hline 3.0 & 3.0 & 4.0 & 5.46 & 6.92 & 8.27 \\
\hline 4.0 & 3.0 & 4.0 & 7.67 & 8.76 & 11.33 \\
\hline 5.0 & 3.0 & 4.0 & 8.22 & 9.34 & 12.55 \\
\hline 3.0 & 1.0 & 4.0 & 5.22 & 6.88 & 8.22 \\
\hline 3.0 & 2.0 & 4.0 & 5.35 & 6.91 & 8.24 \\
\hline 3.0 & 3.0 & 4.0 & 5.46 & 6.92 & 8.27 \\
\hline 3.0 & 4.0 & 4.0 & 5.61 & 7.14 & 8.36 \\
\hline 3.0 & 5.0 & 4.0 & 5.68 & 7.19 & 8.41 \\
\hline 3.0 & 3.0 & 1.0 & 11.22 & 14.48 & 16.89 \\
\hline 3.0 & 3.0 & 2.0 & 7.82 & 10.11 & 12.28 \\
\hline 3.0 & 3.0 & 3.0 & 6.42 & 8.36 & 9.76 \\
\hline 3.0 & 3.0 & 4.0 & 5.46 & 6.92 & 8.27 \\
\hline 3.0 & 3.0 & 5.0 & 4.87 & 6.23 & 7.45 \\
\hline
\end{tabular}

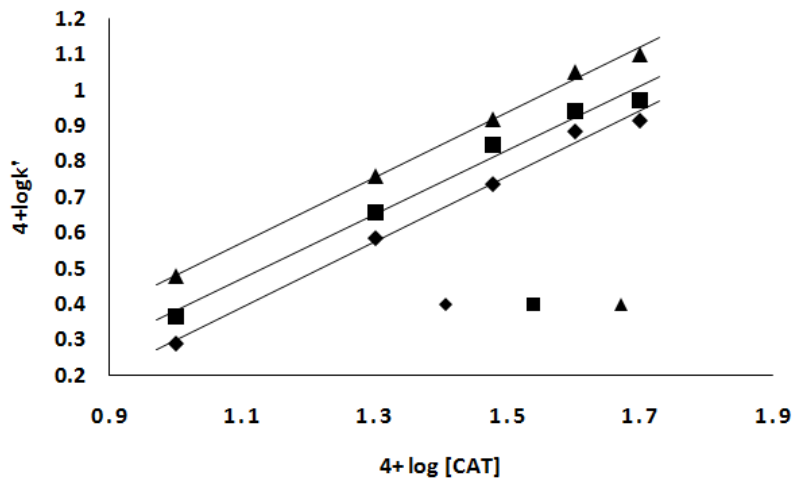

Fig.1: Plot of $\log k^{\prime}$ Vs $\log [\mathrm{CAT}]$

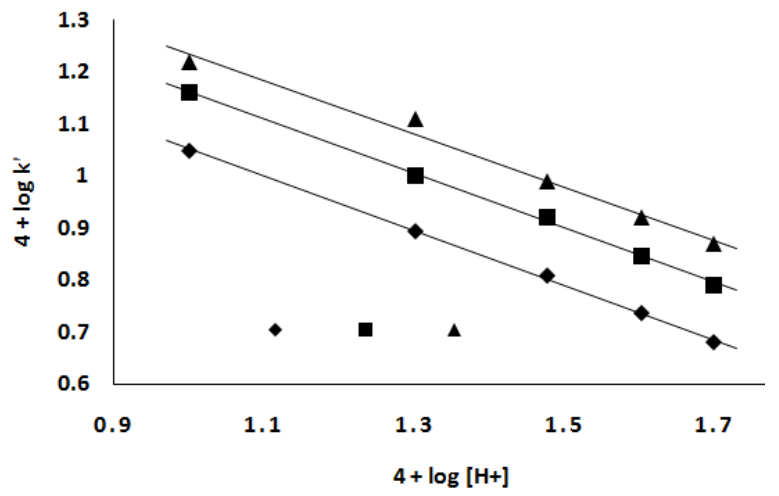

Fig.2: Plot of $\log \mathrm{k}^{\prime}$ Vs $\log$ [CAT]

\subsection{Effect of halide ions, ionic strength and $p$-toluenesulphonamide on the rate}

Addition of halide ions, $\mathrm{Cl}^{-}$and $\mathrm{Br}^{-}$ions in the form of their sodium salts $\left(1.0 \times 10^{-3}-5.0 \times 10^{-3} \mathrm{~mol} \mathrm{dm}^{-}\right.$ ${ }^{3}$ ) had negligible effect on the reaction rate. This suggests that no interhalogen or free halogen is formed in the reaction sequence. Ionic strength $(\mu)$ of the medium was varied byvarying the concentration of Sodium perchlorate $\left.\left(\mathrm{NaClO}_{4}\right)(0.1-0.4 \mathrm{~mol} \mathrm{dm})^{-3}\right)$. No significant effect was noticed. It indicates the involvement of nonionic species in the rate determining step. Hence no attempt was made to keep ionic strength of the medium constant during kinetic runs. The addition of p-toluene sulfonamide (reduction product of CAT) had negative effect on the rate of the reaction which indicates the involvement of the reduction product in a fast preequilibrium to the rate limiting step. Plot of $\log \mathrm{k}^{\prime}$ versus $\log [\mathrm{PTS}]$ were linear $\left(\mathrm{R}^{2}=0.99\right)$ with a negative slope of $0.48,0.36$ and 0.40 for $\mathrm{NO}_{2} \mathrm{BzlH}, \mathrm{BzlH}, \mathrm{OMeBzlH}$ respectively which indicated an inverse fractional order dependence on [PTS] (Figure 3). 
Table 2. Effect of PTS on the rate of the reaction with $[$ subs $]=3.0 \times 10^{-5} \mathrm{~mol} \mathrm{dm}^{-3}[\mathrm{CAT}]=3.0 \times 10^{-4} \mathrm{~mol} \mathrm{dm}^{-3}\left[\mathrm{H}^{+}\right]$ $=4.0 \times 10^{-4} \mathrm{~mol} \mathrm{dm}^{-3}$

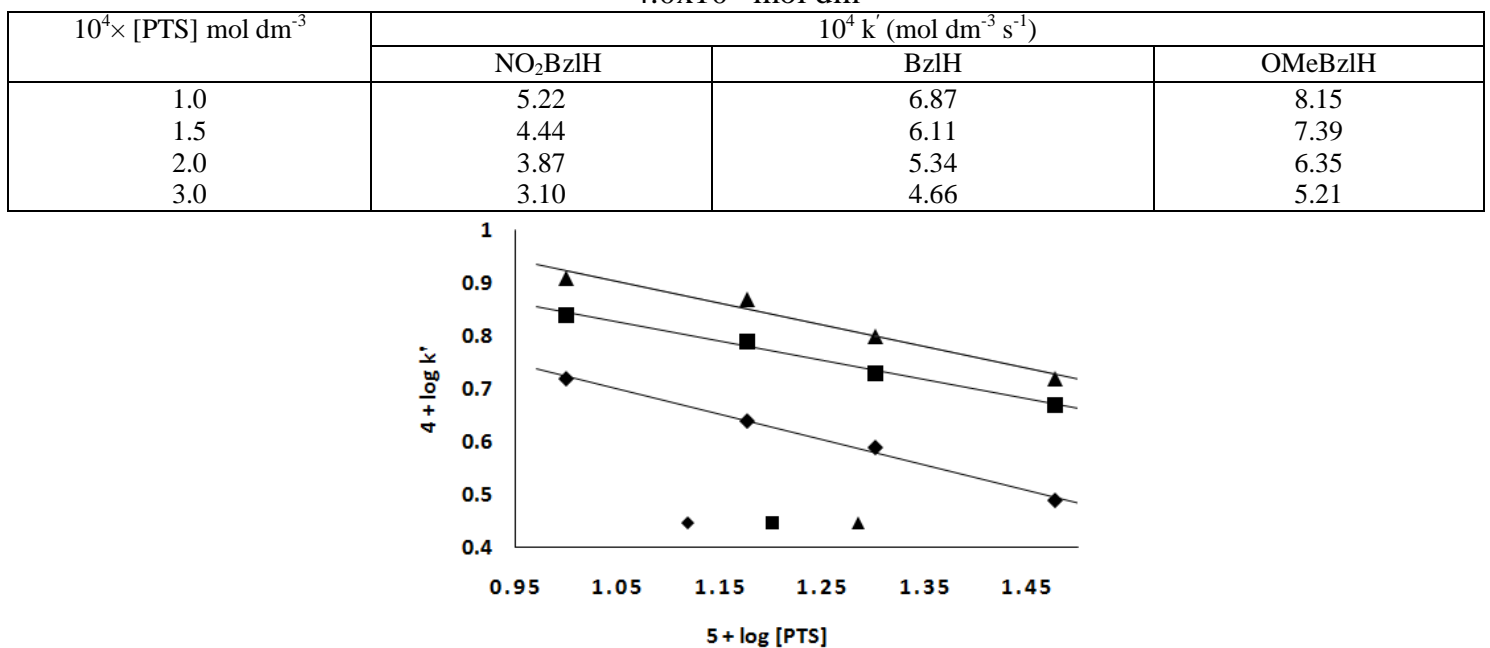

Fig. 3: Plot of $\log k^{\prime}$ Vs $\log$ [PTS]

\subsection{Effect dielectric constant $(D)$ on the rate}

The effect of solvent on the reaction kinetics has been discussed in detail in the well-known monographs of Moelwyn-Hughes [15] Benson [16] Frost and pearson [17] Laidler [18] Amis [19] and Entelis and Tiger [20].The solvent composition was varied by adding methanol (0\%-30\%). The rate of the reaction decreased with the increase in the methanol content of the reaction medium (table 3 ) and plot of logk' vs $1 / \mathrm{D}$ was linear (figure $4, \mathrm{R}^{2}=0.98$ ) with negative slope. Blank experiments with methanol indicated that the oxidation of methanol was negligible. The values of $\mathrm{D}$ for various $\mathrm{MeOH}-\mathrm{H}_{2} \mathrm{O}$ mixtures reported in the literature [21] were employed

Table 3. Effect of dielectric constant on the rate of the reaction with $[\mathrm{subs}]=3.0 \times 10^{-5} \mathrm{~mol} \mathrm{dm}^{-3}[\mathrm{CAT}]=3.0 \times 10^{-}$

\begin{tabular}{|c|c|c|c|c|}
\hline \multirow{2}{*}{$\begin{array}{c}\% \mathrm{MeOH} \\
(\mathrm{v} / \mathrm{v})\end{array}$} & \multirow[t]{2}{*}{ D } & \multicolumn{3}{|c|}{$10^{4} \mathrm{k}^{\prime}\left(\mathrm{mol} \mathrm{dm}^{-3} \mathrm{~s}^{-1}\right)$} \\
\hline & & $\mathrm{NO}_{2} \mathrm{BzlH}$ & BzlH & OMeBzlH \\
\hline 0 & 76.73 & 5.46 & 6.92 & 8.27 \\
\hline 10 & 74.50 & 4.85 & 6.22 & 7.43 \\
\hline 20 & 72.37 & 4.11 & 5.11 & 6.71 \\
\hline 30 & 67.48 & 3.38 & 5.39 & 6.05 \\
\hline
\end{tabular}

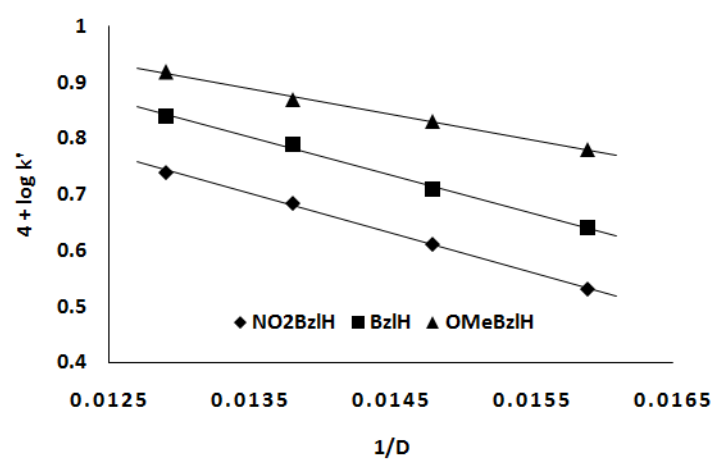

Fig. 4: Plot of $\log k^{\prime}$ Vs 1/D

3.5 Effect of temperature on the rate and calculation of activation parameters

The reaction was studied ad different temperatures in the range 296-312 K keeping other experimental conditions constant. Arrhenius plot of $\log \mathrm{k}^{\prime} \mathrm{Vs} 1 / \mathrm{T}$ were plotted (Figure 5) and with the help of the graph, activation parameters were evaluated and average values for each parameter is reported along with errors (table 4) 
Table 4. Effect of temperature on the rate of the reaction and corresponding values of activation parameters for the oxidation of $\mathrm{NO}_{2} \mathrm{BzlH}, \mathrm{BzlH}$ and $\mathrm{OMeBzlH}$ by CAT in acid medium with $[\mathrm{sub}]=4.0 \times 10^{-5} \mathrm{~mol} \mathrm{dm}^{-3}[\mathrm{CAT}]=$ $3.0 \times 10^{-4} \mathrm{~mol} \mathrm{dm}^{-3}\left[\mathrm{H}^{+}\right]=4.0 \times 10^{-4} \mathrm{~mol} \mathrm{dm}^{3}$

\begin{tabular}{|c|c|c|c|c|c|c|c|}
\hline \multirow{2}{*}{$\mathbf{T}(\mathbf{K})$} & \multicolumn{3}{|c|}{$\mathbf{1 0}^{4} \mathbf{k}^{\prime}\left(\mathbf{m o l ~ d m}^{-\mathbf{3}} \mathbf{s}^{-1}\right)$} & \multicolumn{3}{c|}{ Activation parameters } \\
\cline { 2 - 7 } & $\mathrm{NO}_{2} \mathrm{BzlH}$ & $\mathrm{BzlH}$ & $\mathrm{OMeBzlH}$ & & $\mathrm{NO}_{2} \mathrm{BzlH}$ & $\mathrm{BzlH}$ & 49.87 \\
\hline 296 & 5.46 & 6.92 & 8.27 & $\mathrm{Ea}\left(\mathrm{KJ} \mathrm{mol}^{-1}\right)$ & 73.13 & 39.59 & \\
300 & 8.02 & 8.99 & 9.85 & $\triangle \mathrm{H}^{\#}\left(\mathrm{KJ} \mathrm{mol}^{-1}\right)$ & $59.09 \pm(0.04)$ & $41.30 \pm(0.05)$ & $31.97 \pm(0.04)$ \\
304 & 10.88 & 11.93 & 12.49 & $\triangle \mathrm{G}^{\#}\left(\mathrm{KJ} \mathrm{mol}^{-1}\right)$ & $93.77 \pm(0.06)$ & $93.88 \pm(0.04)$ & $93.61 \pm(0.06)$ \\
308 & 15.49 & 15.43 & 13.31 & $\triangle \mathrm{S}^{\#}\left(\mathrm{JK}^{-1} \mathrm{~mol}^{-1}\right)$ & $-137.03 \pm(0.1)$ & $-167.22 \pm(0.2)$ & $-197.60 \pm(0.2)$ \\
312 & 21.43 & 20.39 & 19.03 & $\log \mathrm{A}$ & $5.85 \pm(0.05)$ & $4.43 \pm(0.04)$ & $3.20 \pm(0.02)$ \\
\hline
\end{tabular}

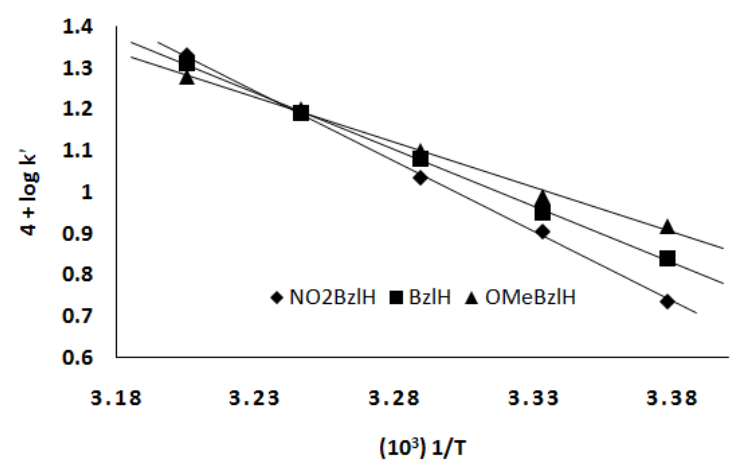

Fig. 5: Plot of $\log \mathrm{k}^{\prime}$ Vs 1/D

\subsection{Test for free radicals}

Addition of reaction mixture to aqueous acrylamide monomer solutions did not initiate polymerization, indicating the absence of in situ formation of free radical species in the reaction sequence

\section{Discussions}

Chloramine-T behaves as a strong oxidizing species in aqueous solutions [22]. Depending on the $\mathrm{pH}$ of the medium; CAT furnishes [22-24] following types of reactive species in solutions:

$$
\begin{aligned}
& \mathrm{TsNCINa} \rightleftharpoons \mathrm{TsNCl}+\stackrel{\ominus}{\ominus} \\
& \stackrel{\ominus}{\ominus} \underset{\mathrm{TsNCl}}{\stackrel{\oplus}{\mathrm{H}} \rightleftharpoons} \mathrm{TsNHCl} \\
& 2 \mathrm{TsNHCl} \rightleftharpoons \mathrm{TsNH}_{2}+\mathrm{TsNCl}_{2} \\
& \mathrm{TsNHCl}+\mathrm{HO}_{2} \rightleftharpoons \mathrm{TsNH}_{2}+\mathrm{HOCl} \\
& \mathrm{TsNCl}_{2}+\mathrm{HO} \rightleftharpoons \mathrm{TsNHCl}+\mathrm{HOCl} \\
& \mathrm{HOCl} \rightleftharpoons \mathrm{H}^{\oplus}+\mathrm{OCl}^{\ominus} \\
& \mathrm{HOCl}+\stackrel{\oplus}{\mathrm{H}} \rightleftharpoons \stackrel{\oplus}{\mathrm{HOCl}}
\end{aligned}
$$

Therefore the possible oxidizing species in acidified CAT solutions are $\mathrm{TsNHCl}, \mathrm{TsNCl}_{2}, \mathrm{HOCl}$, and possibly $\mathrm{H}_{2} \mathrm{O}^{+} \mathrm{Cl}$. Further, formation of species of the type $\mathrm{TsNH}_{2} \mathrm{Cl}^{+}$has been reported $[25$, 26] with CAT and the protonation constant for the reaction,

$$
\mathrm{TsNHCl}+\mathrm{H}^{\oplus} \rightleftharpoons \mathrm{TsNHCl}_{2}^{\oplus}
$$

Is found to be $1.02 \times 10^{2}$ at $25^{\circ} \mathrm{C}$

If $\mathrm{TsNCl}_{2}$ were to be the reactive species, then the rate law predicts a second order dependence of rate on $[\mathrm{CAT}]_{\mathrm{o}}$, which is contrary to the experimental observations. Since the rate of the reaction is retarded by the addition of $\mathrm{TsNH}_{2}, \mathrm{HOCl}$ is the most probable oxidizing reactive species for the oxidation of benzothiazole derivatives in the present system. From the above discussion and experimental facts, scheme $\mathbf{1}$ is proposed to explain the reaction mechanism for the oxidation of benzothiazole derivatives by CAT in $\mathrm{HCl}$ medium In the first step there is a formation of an unprotonated CAT due to deprotonation of $\mathrm{TsNH}_{2} \mathrm{Cl}^{+}$. In the second step unprotonated CAT undergoes hydrolysis to give $\mathrm{TsNH}_{2}$ and $\mathrm{HOCl}$. Here $\mathrm{HOCl}$ is the most probable oxidizing 
species for the oxidation of Benzothiazole derivatives. In the next step (rate determining step) the reactive species forms a complex (X) with Benzothiazole derivative (S) and finally the complex formed undergoes series of changes to give the oxidized products.

$$
\begin{aligned}
& \mathrm{TSNH}_{2} \mathrm{Cl}^{+} \stackrel{\mathrm{K}_{1}}{\rightleftharpoons} \mathrm{TsNHCl}+\mathrm{H}^{+} \text {i) fast } \\
& \mathrm{TsNHCl}+\mathrm{H}_{2} \mathrm{O} \rightleftharpoons \mathrm{K}_{2} \rightleftharpoons \mathrm{TsNH}_{2}+\mathrm{HOCl} \text { ii) fast } \\
& \mathrm{HOCl}+\mathrm{S} \longrightarrow \mathrm{K}_{3} \longrightarrow \mathrm{X} \quad \text { iii) } \quad \text { slow and rds } \\
& \mathrm{X}+\mathrm{H}_{2} \mathrm{O} \longrightarrow \mathrm{K}_{4} \longrightarrow \text { Products iv) fast }
\end{aligned}
$$

Scheme 1: A general scheme for the oxidative decolorization of benzothiazole derivatives by CAT in $\mathrm{HClO}_{4}$ medium.

If [CAT] $]_{t}$ is the total effective concentration of CAT, then

$[\mathrm{CAT}]_{\mathrm{t}}=\left[\mathrm{TsNH}_{2} \mathrm{Cl}^{+}\right]+[\mathrm{TsNHCl}]+[\mathrm{HOCl}]$

From step (i) of scheme 1,

$\mathrm{K}_{1}=\frac{[\mathrm{TsNHCl}]\left[\mathrm{H}^{+}\right]}{\left[\mathrm{TsNH}_{2} \mathrm{Cl}^{+}\right]}$or $\left[\mathrm{TsNH}_{2} \mathrm{Cl}^{+}\right]=\frac{[\mathrm{TsNHCl}]\left[\mathrm{H}^{+}\right]}{\mathrm{K}_{1}}$

From step (ii) of scheme 1,

$$
\mathrm{K}_{2}=\frac{[\mathrm{HOCl}]\left[\mathrm{TsNH}_{2}\right]}{[\mathrm{TsNHCl}]\left[\mathrm{H}_{2} \mathrm{O}\right]} \quad \text { or } \quad[\mathrm{TsNHCl}]=\frac{[\mathrm{HOCl}]\left[\mathrm{TsNH}_{2}\right]}{\mathrm{K}_{2}\left[\mathrm{H}_{2} \mathrm{O}\right]}
$$

By substituting for [TsNHCl] from equation (12) into equation (11) we get

$$
\left[\mathrm{Ts} \mathrm{NH}_{2} \mathrm{Cl}^{+}\right]=\frac{\left[\mathrm{H}^{+}\right][\mathrm{HOCl}]\left[\mathrm{TsNH}_{2}\right]}{\mathrm{K}_{1} \mathrm{~K}_{2}\left[\mathrm{H}_{2} \mathrm{O}\right]}
$$

By substituting for $\left[\mathrm{TsNH}_{2} \mathrm{Cl}^{+}\right][\mathrm{TsNHCl}]$ and $[\mathrm{HOCl}]$ from equation (13) and (12) into equation (10) and solving for [HOCl], we get

$$
[\mathrm{HOCl}]=\frac{\mathrm{k}_{1} \mathrm{k}_{2}[\mathrm{CAT}]\left[\mathrm{H}_{2} \mathrm{O}\right]}{\left[\mathrm{H}^{+}\right]\left[\mathrm{TsNH}_{2}\right]+\mathrm{K}_{1}\left[\mathrm{TsNH}_{2}\right]+\mathrm{K}_{1} \mathrm{~K}_{2}\left[\mathrm{H}_{2} \mathrm{O}\right]}
$$

From slow step of Scheme 1,

Rate $=\mathrm{k}_{3}[\mathrm{HOCl}][\mathrm{S}]$

By substituting for [ $\mathrm{HOCl}]$ from equation 14 , the following rate law is obtained

$$
\text { Rate }=\frac{\mathrm{k}_{1} \mathrm{k}_{2} \mathrm{~K}_{3}[\mathrm{CAT}][\mathrm{S}]\left[\mathrm{H}_{2} \mathrm{O}\right]}{\left[\mathrm{H}^{+}\right]\left[\mathrm{TsNH}_{2}\right]+\mathrm{K}_{1}\left[\mathrm{TsNH}_{2}\right]+\mathrm{K}_{1} \mathrm{~K}_{2}\left[\mathrm{H}_{2} \mathrm{O}\right]}
$$

Rate law (16) satisfactorily fit well to the observed kinetic data wherein a first order dependence of rate on [S] and $[\mathrm{CAT}]$ and inverse fractional order on each $[\mathrm{TsNH} 2]$ and $\left[\mathrm{H}^{+}\right]$on the rate of the reaction .

\section{Conclusions}

All the benzothiazole derivatives exhibit an identical kinetic behavior and the rate of oxidation of benzothiazole derivatives was found to decrease in the order: $\mathrm{OMeBzlH}>\mathrm{BzlH}>\mathrm{NO}_{2} \mathrm{BzlH}$. The Kinetics of Oxidation was studied by CAT as an oxidant in acid medium at $296 \mathrm{~K}$. The experimental rate law was $-\mathrm{d}$ $[\mathrm{CAT}] / \mathrm{dt}=\mathrm{k}\left[\mathrm{NO}_{2} \mathrm{BzlH}\right]^{1}[\mathrm{CAT}]^{0.92}\left[\mathrm{H}^{+}\right]^{-0.52}[\mathrm{PTS}]^{-0.48}$ and $-\mathrm{d}[\mathrm{CAT}] / \mathrm{dt}=\mathrm{k}[\mathrm{BzlH}]^{1}[\mathrm{CAT}]^{0.90}\left[\mathrm{H}^{+}\right]^{0.52}[\mathrm{PTS}]^{-0.36}$ and $\mathrm{d}[\mathrm{CAT}] / \mathrm{dt}=\mathrm{k}[\mathrm{OMeBzlH}]^{1}[\mathrm{CAT}]^{0.90}\left[\mathrm{H}^{+}\right]^{-0.51}[\mathrm{PTS}]^{-0.40}$. The oxidation kinetics was also studied by varying the ionic strength, dielectric constant of the medium. Finally the reaction was studied at different temperatures. Finally based on the observations made an appropriate rate law was derived. 


\section{References}

[1]. S Gupta, N Ajmera,N Gautam, R Sharma and D Gauatam. Novel synthesis and biological activity study of pyrimido [2,1-b] benzothiazoles. Ind J Chem,48B,2009,853-858.

[2]. R.M Kumbhare and V N Ingle, Synthesis of novel benzothiozole and benzisoxazole functionalized unsymmetrical alkanes and study of their antimicrobial activity,Ind J Chem,48B,2009, 996-1000.

[3]. Y.Murthi andD. Pathak, Synthesis and Antimicrobial screening of SubstitutedMercaptobenzothiazoles. J Pharm Res,7(3),2008,153155 .

[4]. B.Rajeeva,N. Srinivasulu andS. Shantakumar, Synthesis and Antimicrobial activity of some new 2-substituted benzothiazolederivatives. E-Journal of Chemistry, 6(3), 2009, 775-779

[5]. M. Maharan,S. William , F. Ramzy andA. Sembel, Synthesis and in vitro Evaluation of new benzothiazolederivaties as schistosomicidal agents,Molecules 12, 2007, 622-633.

[6]. S. Kini,S. Swain and A. Gandhi, Synthesis and Evaluation of novel BenzothiazoleDerivates against Human Cervical Cancer cell lines,Ind JPharm Sci. 2007; Jan-Feb: 46-50.

[7]. H.L.K. Stanton, R Gambari, H.C. Chung, C.O.T.Johny, C. Filly and S.C.C Albert. Synthesis and anti-cancer activity of benzothiazole containing phthalimide on human carcinoma cell lines. Bioorg Med Chem, 16, 2008, 3626-3631.

[8]. M. Wang,M. Gao, B. Mock, K. Miller, G. Sledge, G. Hutchins and Q. Zheng, Synthesis of C-11 labelled fluorinated 2arylbenzothiazoles as novel potential PET cancer imaging agent,Bioorg Med Chem, 14,2006, 8599-8607.

[9]. S. Pattan, C. Suresh, V. Pujar, V. Reddy, V. Rasal andB. Koti, Synthesis and antidiabetic activity of 2-amino[5"(4sulphonylbenzylidine)-2, 4-thiazolidinenone]-7-chloro-6-flurobenzothiazole,Ind J Chem,44B,2005, 2404-2408.

[10]. M. Sreenivasa, E. jaychand, B. Shivakumar, K. Jayrajkumar and J. Vijaykumar, Synthesis of bioactive molecule flurobenzothiazole comprising potent heterocylic moieties for anthelmintic activity, Arch Pharm Sci and Res, 1(2), 2009, $150-157$.

[11]. P. Reddy, Y. Lin ,H. Chang. Synthesis of novel benzothiazole compounds with an extended conjugated system,Arcivoc.16,2007, 113-122.

[12]. Y. Heo, Y. Song, B. Kim and J. Heo, A highly regioselective synthesis of 2-aryl-6 chlorobenzothiazoles employing microwavepromoted Suzuki-Miyaura coupling reaction,Tetrahedron Letters, 47, 2006, 3091-3094.

[13]. F. Piscitelli, C. Ballatore and A. Smith, Solid Phase synthesis of 2- aminobenzothiazoles. Bioorg Med Chem Lett,20, 2010, 644648 .

[14]. J.C. Morris, J.R. Salazar andM.A. Winemann, Equilibrium studies on N-chloro compounds; the ionization constant of N-chloro-ptoluene-sulfonamide,J.Am.Chem.Soc, 54, 1948,2036

[15]. E.A.Moelwyn-Hughes, Phys. Chem., $2^{\text {nd }}$ Ed., Pergamon, New York, 1961

[16]. S. W. Benson, The foundation of Chemical Kinetics, McGraw-Hill, New York, 1960

[17]. A. A. Frostand R.G. Pearson, Kinetics and mechanism, 2nd Ed, Wiley, New York, 1961

[18]. K.J. Laidler, Reaction Kinetics, Pergamon, New York, 1963

[19]. E.S. Amis, Solvent effects on reaction rates and mechanisms, Academic, New York, 1966

[20]. S.G. Entelis and R.P. Tiger, Reaction Kinetics in the liquid phase, Wiley, New York, 1976

[21]. G. Akerloff. J, Am. Chem. Soc, 54, 1932, 412

[22]. E. Bishopand V. J. Jennings, Titrimetric analysis with chloramine-t-i the status of chloramine-t as a titrimetric reagent. Talanta,1,1958, 197.

[23]. F.F. Hardyand J.P Johnton, J. Chem. Soc., Perkin Trans, 2, 1972, 742

[24]. F.G. Soper, Hydrolysis of the p-toluenesulfonchloroamides in water,J. Chem. Soc. Trans, 125,1924, 1899

[25]. S.S. Narayanaand V.R.SRao, Radio Chem. Acta,32, 1983, 1082

[26]. M.M. Subhashini, M. Subrramanianand V.R.S Rao, Determination of the protonation constant of chloramine-B,Talanta, 32, 1985,1082 